\title{
Glioblastoma: Base Conceitual e Perspectivas \\ Futuras de Tratamento
}

\section{Viviane Daneluci de Oliveira* \\ Mayra Dorigan de Macedo* Lidiane Maria Dorigan Brandão* \\ Danielli Gerolin Najm* \\ Patrícia Rodella** \\ Renata Camacho Miziara***}

\section{Resumo}

Glioblastomas são as neoplasias de maior malignidade entre os tumores astrocíticos. O seu prognóstico é ominoso, com poucos anos de sobrevida. Por tratar-se de uma doença tão agressiva, cujo tratamento ainda é bastante limitado, este estudo teve como objetivo, apoiado na literatura, esclarecer seus mecanismos e os avanços em seu tratamento. Conclui-se que, apesar dos progressos no tratamento do glioblastoma, é necessário obter ainda mais avanços por meio de pesquisas promissoras que se encontram em andamento, melhorando, assim, a qualidade de vida dos pacientes.

Palavras-chave: Glioblastoma; Tumor astrocítico; Gene supressor de tumor; Temozolomida; Terapia gênica.

\section{INTRODUÇÃo}

Virchow foi o primeiro a descrever a neuroglia e classificar os tumores cerebrais, colocando gliomas como uma entidade distinta por volta de 1830. Desde então, diversas classificações surgiram (BAILEY; CUSHING, 1926).

Com a cooperação de dez centros internacionais, a Organização Mundial da Saúde (OMS) publicou em 1979 uma classificação histológica dos tumores do

\footnotetext{
*Alunas do Curso de Farmácia do Centro Universitário da Fundação Educacional de Barretos - Unifeb. **Professora do Curso de Farmácia do Centro Universitário da Fundação Educacional de Barretos Unifeb.

***Professora do Curso de Farmácia e Odontologia do Centro Universitário da Fundação Educacional de Barretos - Unifeb. Alameda Estados Unidos; n. ${ }^{\circ} 321$, City Barretos. CEP: 14.784-027; Barretos-SP; Fone: (17) 3322-8465, (17) 3321-6439 ou (17) 3321-6411. E-mail: renatacamacho@ hotmail.com.
} 
Sistema Nervoso Central (SNC). Essa classificação foi posteriormente revista e o resultado, publicado em 1993. Os tumores astrocíticos difusos são divididos em grau II (astrocitoma fibrilar, protoplasmático e gemistocístico), grau III (astrocitoma anaplásico) e grau IV (glioblastoma), enquanto o astrocitoma pilocítico e astrocitoma subependimário de células gigantes são classificados em grau I (FURRER; OSORIO; RONDINELLI et al, 2003).

Os glioblastomas são as neoplasias de maior malignidade entre os tumores astrocíticos, podendo ser originados de um astrocitoma de menor grau de malignidade (glioblastoma secundário) ou, mais frequentemente, sem evidências de neoplasia precursora (glioblastoma primário). Os glioblastomas secundários ocorrem após meses ou anos (quatro a cinco anos) de um astrocitoma de grau II ou de grau III (FURRER; OSORIO; RONDINELLI et al., 2003).

São tumores que ocorrem mais frequentemente após os 50 anos, com um pico na sexta década, história clínica mais curta, crescimento rápido e prognóstico sombrio. É raro na idade pediátrica, mas, quando surge, atinge crianças na primeira década de vida e se manifesta com lesões de alta agressividade clínica. Há discreto predomínio do sexo masculino em termos de incidência, com proporção de 3:2, sendo também mais elevada na raça branca (RONDINELLI; MARTINEZ, 2002; SANTOS; SARAIVA; SANTIAGO, 2003; GROSSMAN; BATARA, 2004).

\section{Alterações genéticas envolvidas na fOrmaÇão doS tUmores}

A formação dos tumores astrocíticos do sistema nervoso central, tal como a de outros tumores humanos, é um processo complexo que ocorre pelo acúmulo de alterações genéticas, envolvendo principalmente dois grupos principais de genes ligados à regulação da proliferação celular: os proto-oncogenes, associados à regulação positiva da proliferação celular, e quando alterados chamados oncogenes; e os genes supressores de tumor, que ao contrário, atuam restringindo a proliferação celular (FURRER; OSORIO; RONDINELLI et al, 2003).

\section{Oncogenes}

Os oncogenes são atualmente classificados em quatro grupos, de acordo com seu modo de atuação: 1) os fatores de crescimento; 2) os receptores para fatores de crescimento; 3 ) os transdutores de sinal; e 4) os fatores de transcrição (BRENTANI; COELHO; KOWALSKI, 2003).

Os fatores de crescimento são proteínas que estimulam a célula a se dividir. $\mathrm{Na}$ ausência dessas proteínas, a célula normal sai do seu ciclo de divisão e entra em um estado quiescente, conhecido como G0. Vários oncogenes codificam 
proteínas que influenciam o crescimento e a diferenciação celular. Na maioria dos casos, as mutações oncogênicas desses genes aumentam a quantidade de proteína produzida, sem alterar sua estrutura molecular (BRENTANI; COELHO; KOWALSKI, 2003). Diversos fatores de crescimento e seus receptores estão superexpressos nos astrocitomas, incluindo o PDGF (fator de crescimento derivado de plaqueta), os fatores de crescimento fibroblástico (FGFs) e o fator de crescimento endotelial vascular (VEGF) (FURRER; OSORIO; RONDINELLI et al, 2003).

A segunda classe de oncogenes corresponde aos receptores para fatores de crescimento presentes na superfície da célula. Os receptores são proteínas transmembrânicas, com um domínio externo ao qual se liga o fator de crescimento e um domínio citoplasmático capaz de ativar a cascata de sinalização intracelular. Alterações estruturais ou a superprodução desses receptores têm sido identificadas em alguns tumores, resultando na ativação da proliferação celular mesmo na ausência de estímulo extracelular. Exemplo de um receptor para fatores de crescimento que age como oncogene quando alterado é o receptor do fator de crescimento epidermal (EGFR) (codificado pelo $c$-erbB) (BRENTANI; COELHO; KOWALSKI, 2003). O oncogene EGFR é o gene mais frequentemente amplificado nos tumores astrocíticos encontrado em $50 \%$ dos glioblastomas e em poucos astrocitomas anaplásicos (FULLER; BIGNER, 1992). O aumento de expressão do EGFR (WONG; BIGNER; BIGNER et al., 1987) constitui uma característica marcante do glioblastoma primário, sendo observado em mais de 60\% destes tumores (WATANABE; TACHIBANA; SATO et al., 1996).

A terceira classe dos oncogenes compreende as proteínas localizadas na face interna da membrana citoplasmática, as quais estão envolvidas no processo de sinalização intracelular. Essas proteínas atuam em vias complexas, como transdutoras ou amplificadoras de sinal desencadeado pela ligação do fator de crescimento e seu receptor. Alterações nos comandos de proliferação celular podem ocorrer quando essas proteínas sofrem mudanças estruturais que fazem com que elas emitam sinais proliferativos, mesmo na ausência de estímulo externo. Exemplos desta classe são c-abl e ras (BRENTANI; COELHO; KOWALSKI, 2003).

A última classe de proto-oncogenes engloba proteínas nucleares que agem como fatores de transcrição regulando diretamente a expressão gênica. Os fatores de transcrição possuem em sua estrutura domínios protéicos capazes de interagir com a região promotora dos genes, assim como com outros membros do mecanismo de transcrição da célula. Os fatores de transcrição frequentemente relacionados à formação de tumores são as proteínas das famílias myc, fos e 
jun. Na ausência de fatores de crescimento, esses genes se encontram desligados e seus produtos são indetectáveis na célula; no entanto, na presença destes, quantidades dessas proteínas se acumulam rapidamente no núcleo e são capazes de ativar uma série de genes (BRENTANI; COELHO; KOWALSKI, 2003).

\section{Genes supressores de tumor}

O gene RB1 (Retinoblastoma) foi o primeiro gene supressor de tumor a ser descrito - ele codifica uma proteína de 928 aminoácidos que se localiza predominantemente no núcleo e é expressa na maioria dos tecidos. Essa proteína regula o ciclo celular e, na sua forma ativa, é capaz de paralisar a célula na fase G0/G1 do ciclo celular, bloqueando o avanço para a fase $\mathrm{S}$ (síntese de DNA) (BRENTANI; COELHO; KOWALSKI, 2003). Como mutações no RB1 apresentam a mesma consequência funcional que a amplificação CDK4/CDK6 (Kinases dependentes de ciclinas 4 ou 6) ou mutação de CDKN2A e CDKN2B (Inibidores de Kinases-dependentes de ciclinas), esses eventos costumam ocorrer isoladamente, em grande proporção, nos astrocitomas anaplásicos e em quase todos glioblastomas (ICHIMURA; SCHMIDT; GOIKE et al., 1996; UEKI; ONO; HENSON et al., 1996).

O gene supressor de tumor p53 encontra-se alterado em 50\% dos tumores humanos e possui características importantes tanto no controle do ciclo celular como nos mecanismos de reparo de DNA. A proteína codificada por esse gene foi nomeada p53 e, assim como o gene RB1, possui localização nuclear. A proteína p53 possui um papel muito importante na célula, pois ela atua como "guardiã" do genoma. Ela age antes da síntese de DNA, durante a divisão mitótica, "verificando" se a molécula de DNA está íntegra para que o ciclo celular possa seguir adiante. Se algum problema grave é detectado, há duas possibilidades para a célula: ativar o sistema de reparo via p53 ou, no caso de existirem múltiplas lesões, a opção é a morte celular programada (MCP) ou apoptose. Em células com o gene p53 mutado ou inativo, há um acúmulo de defeitos genéticos que culminam na transformação maligna, pois não ocorre apoptose. Recentemente, verificou-se que a proteína p53 é capaz de ativar vários genes celulares que atuam nos processos de integridade genômica e divisão celular. Um exemplo é o gene p21, um inibidor de quinases dependentes de ciclinas (BRENTANI; COELHO; KOWALSKI, 2003).

A inativação do p53 parece exercer um papel essencial na gênese dos astrocitomas de baixo grau e na progressão até o glioblastoma secundário, enquanto mutações são raras no glioblastoma primário $(<10 \%)$ (WATANABE; TACHIBANA; SATO et al., 1996). No estudo de Cheng e colaboradores 
(1999), com 24 astrocitomas de alto grau (11 astrocitomas anaplásicos e 13 glioblastomas), foi encontrada mutação no gene p53 em 38\% dos tumores (9/ 24). Essa alteração fica mais evidente quando os tipos de glioblastomas são analisados separadamente. A frequência de mutação p53 é rara nos glioblastomas primários $(<10 \%)$ e tem uma alta incidência nos glioblastomas secundários (>65\%) (WATANABE; SATO; BIERNAT et al., 1997). O gene p53 é inativado preferencialmente por mutações pontuais. É um evento precoce e peculiar dos glioblastomas secundários, assim como a perda da heterozigose do cromossomo 17p. Nos glioblastomas primários há a amplificação do gene EGFR (Epidermal Growth Factor Receptor) e perda da heterozigose do cromossomo 10 (FURRER; OSORIO; RONDINELLI et al, 2003).

\section{Características do tumor}

O aspecto macroscópico é o de um tumor infiltrativo, acinzentado, pobremente definido, que se expande e distorce o cérebro invadido. Esses tumores variam em tamanho de alguns centímetros até lesões enormes que substituem um hemisfério inteiro. A superfície de corte do tumor pode ser firme ou macia e gelatinosa, e a degeneração cística normalmente é visível. É característico ocorrer variações na aparência macroscópica de região para região. Algumas áreas são firmes e brancas, outras são macias e amarelas (o resultado da necrose tecidual), e outras ainda mostram regiões de degeneração cística e hemorragia. O tumor pode parecer bem demarcado do tecido cerebral circunjacente, porém a infiltração para além das margens externas está sempre presente (KUMAR; ABBAS; FAUSTO et al, 2005).

O glioblastoma tem um aspecto histológico que mostra regiões mais densamente celulares e um maior pleomorfismo nuclear; células com atividade mitótica são frequentemente observadas. Apresenta características de necrose e proliferação vascular ou celular endotelial, cada uma com um aspecto estereotípico. A necrose, frequentemente com padrão serpentiforme, ocorre nas áreas de hipercelularidade, com células tumorais altamente malignas aglomeradas ao longo das margens das regiões necróticas, produzindo um padrão histológico referido como pseudopaliçada. Na situação chamada de gliomatose cerebral, múltiplas regiões do cérebro, e, em alguns casos, o cérebro inteiro estão infiltrados por astrócitos neoplásicos (KUMAR; ABBAS; FAUSTO et al, 2005).

\section{Sinais E SINTOMAS do glioblastoma}

Os sinais e sintomas apresentados resultam, de um modo geral, da infiltração ou compressão pelo tumor do tecido cerebral normal, do edema peritumoral e, 
por vezes, da hemorragia (CORREIA; ALEXANDRE; DIAS et al., 2009). A vascularização e o líquido cefalorraquidiano podem também estar comprometidos, levando a déficits neurológicos progressivos e ao aumento da pressão intracraniana (GROSSMAN; BATARA, 2004).

A sintomatologia produzida pode dividir-se em específica e não específica. A específica é provocada pela localização intracraniana do tumor. Manifesta-se por sinais neurológicos lateralizadores como a paresia, a afasia e os déficits visuais. As convulsões são um sintoma comum, ocorrendo em cerca de $25 \%$ dos gliomas de alto grau que podem ser parciais ou generalizadas. A hemorragia tumoral está, geralmente, associada com os gliomas de alto grau, ocorrendo em 5 a $8 \%$ dos glioblastomas. A hemorragia pode apresentar-se como um acidente vascular cerebral. As alterações do estado de consciência associadas às cefaléias sugerem uma hemorragia intracraniana, em vez de um enfarte cerebral (CORREIA; ALEXANDRE; DIAS et al., 2009).

A sintomatologia não específica é representada pelas cefaléias, náuseas e vômitos que são provocados pelo aumento da pressão intracraniana. $\mathrm{O}$ papiledema é, atualmente, visto em menos de $10 \%$ dos casos, mesmo quando os sintomas de aumento da pressão intracraniana estão presentes (DEANGELIS; LOEFFLER; MAMELAK, 2004).

\section{Diagnóstico e Sobrevida}

A ressonância magnética nuclear é o método de diagnóstico de eleição a ser usado nos sinais e sintomas sugestivos de massa intracraniana, devendo ser realizada com e sem contraste (gadolinium) (CORREIA; ALEXANDRE; DIAS et al., 2009). A tomografia computadorizada contrastada pode ser usada, se a ressonância magnética nuclear não estiver disponível ou se houver contraindicação à realização desta última (exemplo: portador de Pacemaker) (DEANGELIS; LOEFFLER; MAMELAK, 2004).

Topograficamente, os glioblastomas predominam na região supratentorial. Surgem com mais frequência nos lobos temporal (32\%), frontal (31\%), frontoparietal (11\%), parietal (10\%), temporoparietal (7\%) e nas regiões occipitoparietais (5\%). São pouco comuns no terceiro ventrículo e raramente ocorrem na fossa posterior (SANTOS; SARAIVA; SANTIAGO, 2003).

O diagnóstico definitivo apenas pode ser afirmado histologicamente. Como são tumores heterogêneos, uma só biópsia aspirativa pode não ser representativa da totalidade do tumor. Os achados histológicos primários incluem: pseudopaliçada, necrose, celularidade aumentada, pleomorfismo, mitoses e proliferação endotelial vascular (GROSSMAN; BATARA, 2004). 
A sobrevida média dos doentes com glioblastoma é de 9 a 12 meses. A maioria morre dentro de dois anos e menos de $5 \%$ sobrevive cinco anos (CORREIA; ALEXANDRE; DIAS et al., 2009).

\section{Tratamento}

A terapêutica desses tumores engloba duas vertentes: a de suporte e a definitiva (DEANGELIS; LOEFFLER; MAMELAK, 2004). O tratamento de suporte tem como objetivo o alívio sintomático e a melhoria da função neurológica. Os agentes de primeira linha são os anticonvulsivantes e os corticosteroides. Os anticonvulsivantes são administrados aos que apresentam convulsão na apresentação da neoplasia. Os corticosteroides reduzem o edema peritumoral, o efeito de massa e a pressão intracraniana. Esses efeitos produzem alívio imediato das cefaléias e melhoram os sinais neurológicos. O tratamento definitivo inclui a cirurgia, a radioterapia e a quimioterapia (CORREIA; ALEXANDRE; DIAS et al., 2009).

\section{Cirurgia}

A disseminação precoce de células malignas torna o glioblastoma incurável cirurgicamente. Contudo, a cirurgia desempenha um papel fundamental na abordagem dos doentes com a suspeita dessa neoplasia. A neurocirurgia permite obter tecido cerebral para o estabelecimento de um diagnóstico correto, alivia os sintomas resultantes do efeito de massa e diminui a necessidade de corticoterapia. Ademais, a cirurgia agressiva, em que se remove a maior parte do tumor, reduz o número de células cancerosas que necessitam de tratamento e, muitas vezes, remove o núcleo hipóxico do tumor, que é relativamente resistente à radiação e inacessível à quimioterapia. Existem controvérsias em relação à extensão da cirurgia e à sobrevida dos pacientes. No entanto, pensa-se que o melhor tratamento consiste na maior remoção possível de massa tumoral sem causar danos neurológicos (CORREIA; ALEXANDRE; DIAS et al., 2009). Independentemente disso, a excisão completa é raramente atingida, especialmente nos glioblastomas de hemisférios cerebrais, uma vez que as células malignas infiltram além das margens identificadas à tomografia computadorizada e/ou ressonância magnética (AMMIRAT; VICK; LIAO et al., 1987; CAMPBELL; POLLACK; MARTINEZ et al., 1996).

A morbidade neurológica do procedimento é de $8 \%$ e a mortalidade, de 2,7\% (SALCMAN, 1998). Quando, por algum motivo, o risco da cirurgia supera os benefícios deve-se realizar uma biópsia, que pode ser estereotáxica, cuja morbimortalidade é pequena. Ela proporciona o diagnóstico anatomopatológico 
em mais de $90 \%$ dos casos, permitindo a administração de radioterapia e quimioterapia com embasamento histopatológico (HALPERIN; BENTEL; HEINZ et al, 1989). Esse tipo de biópsia é, geralmente, reservada para tumores localizados em zonas mais profundas, em áreas cerebrais importantes ou em doentes com lesões extensas, nos quais não será possível obter-se a excisão total (GROSSMAN; BATARA, 2004).

\section{Radioterapia}

A radioterapia é um aspecto importante do tratamento dos glioblastomas. Ela prolonga a sobrevida e geralmente melhora ou mantém a função neurológica. Isoladamente é o tratamento mais eficaz para este tumor (McCORMICK; TORRES; POST et al., 1990). No entanto, apenas radioterapia adjuvante para os tumores completamente ressecados proporciona menos de $25 \%$ de controle no longo prazo (COKGOR; FRIEDMAN; FRIEDMAN, 1998). Para as ressecções incompletas, posteriormente irradiadas, a medida de sobrevida raramente excede um ano e meio e de 0-30\% dos pacientes sobrevivem além de três anos (ANDERSEN, 1978; DUFFNER; COHEN; MYERS et al., 1986; DROPCHO; WISOFF; WALKER et al., 1987; REVESZ; SCARAVILLI; COUTRINHO et al., 1993).

\section{Quimioterapia}

A quimioterapia tinha um benefício limitado no tratamento dos gliomas malignos e não aumentava de um modo significativo a sobrevida média (DEHDASHTI; HEGI; REGLI et al., 2006). Atualmente, com a utilização da temozolomida e outros agentes quimioterápicos mais recentes, que atuam no nível da inibição da tirosina quinase, do receptor do fator de crescimento da epiderme (epidermal growth factor receptor - EGFR) e do fator de crescimento do endotélio vascular (vascular endothelial growth factor - VEGF), entre outros, parece trazer algum aumento de sobrevida a esses doentes (CORREIA; ALEXANDRE; DIAS et al., 2009).

A temozolomida foi aprovada em 1999, pela Food and Drugs Administration (FDA), no tratamento do astrocitoma anaplásico recorrente e, em 2005, no do glioblastoma recém-diagnosticado (COHEN; JOHNSON; PAZDUR, 2005). É um agente alquilante de administração oral. Atravessa a barreira hematoencefálica, apresentando concentrações no líquor de $20 \%$ a $40 \%$ das plasmáticas. O potencial desse fármaco, administrado sozinho ou em associação à radioterapia, tem sido avaliado em ensaios randomizados, cujos resultados sugerem um significativo prolongamento da sobrevida (COHEN; JOHNSON; 
PAZDUR, 2005; DEHDASHTI; HEGI; REGLI et al, 2006; STUPP; HEGI; VAN DEN BENT et al, 2006).

\section{Associações indicadas}

Sempre que a doença for localizada e ressecável, o paciente deve ser submetido a uma cirurgia visando à ressecção máxima, seguida de radioterapia associada à temozolomida. A seguir, os pacientes devem receber temozolomida por mais seis meses após a radioterapia. Nos pacientes inoperáveis ela pode ser usada também junto com a radioterapia, e em pacientes recidivados, que já tenham feito radioterapia no passado, a temozolomida deve ser usada como agente isolado em cinco dias consecutivos a cada 28 dias (KATZ, 2003).

É de salientar que, potencialmente, todos os gliomas malignos recidivarão, seja qual for o tratamento inicial utilizado. Os doentes podem beneficiar-se da reoperação, de técnicas de radioterapia local (radiocirurgia) e de outros diferentes agentes quimioterápicos (RONDINELLI; MARTINEZ, 2002; DEANGELIS; LOEFFLER; MAMELAK, 2004; GROSSMAN; BATARA, 2004).

\section{Perspectivas futuras: intervenção gênica}

O acúmulo de conhecimentos sobre os mecanismos do câncer e a habilidade dos pesquisadores para introduzir genes exógenos em células de mamíferos têm levado ao desenvolvimento de protocolos de transferência gênica, visando ao tratamento do câncer. Resultados pré-clínicos, obtidos em modelos animais, indicam o potencial de uma grande variedade de estratégias de intervenção gênica como forma de tratamento. As estratégias mais promissoras e utilizadas em protocolos experimentais de terapias gênicas do câncer são (FRIEDMANN; ROBLIN, 1972): reposição de genes supressores de tumor nas células do câncer (FRIEDMANN, 2001); inserção de gene suicida (VERMA; SOMIA, 1997); inserção de gene de resistência ou proteção nas células hematopoiéticas do paciente (MOUNTAIN, 2000).

\section{Reposição de genes supressores de tumor}

Pesquisadores do Instituto de Ciências Biomédicas (ICB) da Universidade de São Paulo (USP) elaboram um protocolo de terapia gênica contra o glioblastoma. A meta é inibir o tumor com genes supressores: eles controlam o ciclo celular, impedindo a reprodução desordenada de células que caracterizam o câncer. Presentes nas células normais, esses genes foram perdidos pelas tumorais. Trata-se de repô-los com vetores virais. Para montar o vetor, combinam-se duas sequências moleculares ou plasmídios: uma carregada com o 
gene ou os genes terapêuticos; outra, com genes que conferem ao conjunto as características de um vírus. Ambas são acopladas por células empacotadoras com alta capacidade de síntese proteica. Quando os plasmídios se combinam, o resultado é um vírus totalmente manipulado, capaz de comunicar às células-alvo os genes de interesse. Esse vírus é incapaz de replicar-se. Infecta as células uma única vez, o que garante que o processo não escape ao controle. Os pesquisadores construíram vírus recombinantes, portadores de genes supressores do tumor, e demonstraram que não há um gene supressor único capaz de inibir todos os casos de glioblastoma. No câncer, os genes de interesse são p16, p21, p53 e $\mathrm{pRb}$. Presentes no organismo sadio, são frequentemente perdidos pelo tecido tumoral e devem ser repostos. O p53 e o p16 são especialmente importantes: o primeiro provoca a morte das células e o segundo induz seu envelhecimento. Sem a ação inibidora de ambos, as células cancerosas se multiplicam descontroladamente. Infectadas por um vírus que carregue os dois genes, as células recebem um forte estímulo para parar de crescer, até mesmo para morrer, e tornam-se vulneráveis à radioterapia (STRAUSS, 2002).

\section{Inserção de gene suicida}

A inserção de gene suicida consiste em usar adenovírus como vetor, o qual carrega pares de genes suicidas fundidos diretamente para as células cancerosas, sensibilizando-as. Esse procedimento é seguido da administração de prómedicamentos, resultando na secreção de substância tóxica dentro das mesmas, levando-as a cometer suicídio.

\section{Inserção de gene de resistência ou proteção nas células hematopoiéticas}

A inserção de gene de resistência ou proteção nas células hematopoiéticas do paciente é a introdução do gene MDR1 (Multidrug Resistance Gene) em células tronco-hematopoiéticas de pacientes com câncer, conferindo as mesmas elevada resistência aos efeitos tóxicos de quimioterápicos. Essa resistência permite o tratamento de tumores sólidos com altas doses de quimioterápicos, levando a melhores resultados no tratamento (FURRER; OSORIO; RONDINELLI et al, 2003).

\section{Perspectiva futura: terapia biológica}

A terapia biológica (imunoterapia) contra o câncer é reconhecida como outra modalidade de tratamento sistêmico. Caracteriza-se pela utilização de drogas que são coletivamente chamadas de "modificadores da resposta biológica", tais como interleucinas, interferons e fator de necrose tumoral. O desenvolvimento 
desse novo arsenal terapêutico está intimamente relacionado aos avanços no conhecimento da biologia tumoral e nas técnicas de biotecnologia (BRENTANI; COELHO; KOWALSKI, 2003).

O presente progresso no desenvolvimento da biologia molecular tem proporcionado uma melhor compreensão do mecanismo das interações complexas do sistema imune com a célula tumoral. O domínio do mecanismo da resposta imune poderá resultar no desenvolvimento de uma estratégia efetiva na erradicação dos tumores cerebrais, preservando as células normais do SNC, utilizando as defesas naturais do organismo (FURRER; OSORIO; RONDINELLI et al., 2003).

\section{Conclusões}

Tendo como base as informações apresentadas nesta revisão, conclui-se que o glioblastoma é um câncer muito agressivo e de baixa sobrevida. Apesar de o mecanismo de formação desse câncer ser bastante conhecido, o tratamento ainda é pouco eficiente, com resultados pouco significativos para o aumento da sobrevida e melhora na qualidade de vida dos pacientes. No entanto, há atualmente muitas pesquisas sendo realizadas em busca de melhores resultados, as quais levam à perspectivas futuras promissoras.

\section{REFERÊNCIAS}

AMMIRATI, M.; VICK, N.; LIAO, Y. et al. Effect of the exytent of surgical resection on survival and quality of life in patients with supratentorial glioblastomas and anaplastic astrocytomas. Neurosurgery, v.21, p. 201-6, 1987.

ANDERSEN, A. P. Postoperative irradiation of glioblastomas: results in a randomized series. Acta Radiol Oncol, v.17, p. 475-84, 1978.

ARAÚJO, M. B. M. Classificação dos tumores do Sistema Nervoso Central. In: FURRER, A. A.; OSORIO, C. A. N.; RONDINELLI, P. I. P. et al. Neurologia Oncológica Pediátrica: Manejo Multidisciplinar das Neoplasias do Sistema Nervoso Central da Infância. São Paulo: Lemar, 2003. cap. 6, p. 68.

\section{BAILEY, P.; CUSHING, H. A classification of tumors of the glioma} group. Philadelphia: J. B. Lippincott; 1926.

CAMARGO, A. A.; COSTA, F. F. Oncogenes e genes supressores de tumor. In: BRENTANI, M. M.; COELHO, F. R. G.; KOWALSKI, L. P. Bases da 
Oncologia. 2. ed. São Paulo: Lemar, cap. 5, p. 74-77, 2003.

CAMPBELL, J. W.; POLLACK, I. F.; MARTINEZ, A. Z. et al. High grade astrocytomas in children: radiologically complete resection is associated with an excellent long-term prognosis. Neurosurgery, v. 38, p. 258-64, 1996.

CHENG, Y.; NG, H. K.; ZHANG, S. F. et al. Genetic alterations in pediatric high-grade astrocytomas. Hum Pathol, v.30, p.1284-90, 1990.

COHEN, M. H.; JOHNSON, J. R.; PAZDUR, R. Food and Drugs Administration approval summary: temozolomide plus radiation therapy for the treatment of newly diagnosed glioblatoma multiforme. Clin Cancer Res. v.11, n.19, p. 6767-6771, 2005.

COKGOR, I.; FRIEDMAN, A. H.; FRIEDMAN, H. S. Gliomas. Eur J Cancer, v.34, p. 191-1918, 1998..

CORREIA, J.; ALEXANDRE, J. C.; DIAS, C. et al. Glioblastoma Multiforme-A propósito de um caso clínico. Revista da Sociedade Portuguesa de Medicina Interna, Lisboa, v. 16, n.1, p. 27-32, jan/mar, 2009.

DEANGELIS, L. M.; LOEFFLER, J. S.; MAMELAK, A. N. Primary brain tumors. Câncer management. A multidisciplinary approach. 8 . ed. 2004.

DEHDASHTI, A. R.; HEGI, M. E.; REGLI, L. et al. New trends in medical management of glioblastoma multiforme: the role of temozolomide chemotherapy. Neurosurg Focus, v. 20, n. 4, p. E6, 2006.

DROPCHO, E. J.; WISOFF, J. H.; WALKER, R. W. et al. Supratentorial malignant gliomas in childhood: a review of fifty cases. Ann Neurol, v. 22, p.355-64, 2004.

DUFFNER, P. K.; COHEN, M. E.; MYERS, M. H. et al. Survival of children with brain tumors: SEER program. Neurology, v.36, p. 597-601, 1986.

FRIEDMANN, T.; ROBLIN, R. Gene therapy for human genetic disease? Science, v. 175, n. 25, p.949-955, 1972. 
FRIEDMANN, T. Stanfield Rogers: insights into virus vectors and failure of an early gene therapy model. Mol Ther, v. 4, n. 4, p.285-288, 2001.

FROSCH, M. P.; ANTHONY, D. C.; GIROLAMI, U. O sistema nervoso central. In: KUMAR, V. Y.; ABBAS, A. K.; FAUSTO, N. et al. Robbins \& Cotran. Patologia: Bases Patológicas das Doenças, 7. ed. Rio de Janeiro: Elsevier 2005. cap. 28, p. 1468.

FULLER, G. N.; BIGNER, S. H. Amplified cellular oncogenes in neoplasms of the human central nervous system. Mutat Res, v.276, p. 299-306, 1992.

GROSSMAN, S. A.; BATARA, J. F. Current management of Glioblastoma Multiforme: Seminars in Oncology. Rio de Janeiro: Elsevier, 2004.

HALPERIN, E. C.; BENTEL, G.; HEINZ, E. R. et al. Radiation therapy treatment planning in supratentorial glioblastoma multiform: an analysis based on post mortem topographic anatomy with CT correlations. Int J Radiat Oncol Biol Phys., v. 17, p. 1347-50, 1989.

ICHIMURA, K.; SCHMIDT, E. E.; GOIKE, H. M. et al. Human glioblastomas with no alterations of CDK2A (p16INK4A, MTS1) and CDK4 genes have frequent mutations of the retinoblastoma gene. Oncogene, 1936; 13: 1065-72.

KATZ, A. Avanços no tratamento de gliomas malignos. Prática Hospitalar. São Paulo, v. 5, n. 30, nov/dez 2003.

McCORMICK, P. C.; TORRES, R.; POST, K. D. et al. An intramedullary ependymona of the spinal cord. J Neurosurgv.72, p. 523-532, 1990.

MELO, S. M.; BARBUTO, J. A.; BENABOU, S. Gliomas malignos Imunologia e Imunoterapia. In: FURRER, A. A.; OSORIO, C. A. N.; RONDINELLI, P. I. P. et al. Neurologia Oncológica Pediátrica: Manejo Multidisciplinar das Neoplasias do Sistema Nervoso Central da Infância. São Paulo: Lemar - Livraria Editora Marina e Tecmed Editora, 2003. cap. 15, p. 187.

MOUNTAIN, A. Gene therapy: the first decade. Trends Biotechnol, v.18, n.3, p.119-128, 2000. 
OSORIO, C. A. M. Astrocitoma Supratentoriais. In: FURRER, A. A.; OSORIO, C. A. N.; RONDINELLI, P. I. P. et al. Neurologia Oncológica Pediátrica: Manejo Multidisciplinar das Neoplasias do Sistema Nervoso Central da Infância. São Paulo: Lemar, 2003. Cap. 23, p.383

PIZÃO, P. E. Terapia biológica. In: BRENTANI, M. M.; COELHO, F. R. G.; KOWALSKI, L. P. Bases da Oncologia. 2. ed. São Paulo: Lemar - Livraria Editora Marina e Tecmed Editora, 2003. cap. 23, p. 383.

REVESZ, T.; SCARAVILLI, F.; COUTRINHO, L. et al. Realibility of histological diagnosis including grading in gliomas biopsed by image-guided stereotactic technique. Brain, p. 116-93, 1993.

ROCHA, J. C. C. Biologia Molecular dos Tumores do Sistema Nervoso Central. In: FURRER, A. A.; OSORIO, C. A. N.; RONDINELLI, P. I. P. et al. Neurologia Oncológica Pediátrica: Manejo Multidisciplinar das Neoplasias do Sistema Nervoso Central da Infância. São Paulo: Lemar Livraria Editora Marina e Tecmed Editora, 2003. cap. 8, p. 89, 90.

RONDINELLI, P. I. P.; MARTINEZ, C. A. O. Metástases intrarraquidianas de Glioblastoma Multiforme supratentorial da infância. Arquivo Neuropsiquiatria, 2002; 60 (3-A): 643-646.

SALCMAN, M. Gliomas malignos. In: SIQUEIRA, M. C.; NOVAES, V., editores. Tumores intracranianos: biologia, diagnóstico e tratamento. São Paulo: Revinter, 1998; p. 34-45.

SANTOS, A. V.; SARAIVA, P. F.; SANTIAGO, B. Metastização extracraniana de Glioblastoma multiforme. Acta Médica Portuguesa, 2003; 16: 209-211.

STRAUSS, E. C. Medicamentos à base de vírus: Produção de vetores faz avançar a terapia gênica, alternativa de tratamento de doenças como o câncer de cérebro. Revista Pesquisa FAPESP, São Paulo, v.78, ago/2002,

STRAUSS, E. C.; STRAUSS, B. E. Terapia gênica e o desafio de uma nova estratégia de tratamento do câncer. In: FURRER, A. A.; OSORIO, C. A. N.; RONDINELLI, P. I. P. et al. Neurologia Oncológica Pediátrica: Manejo 
Multidisciplinar das Neoplasias do Sistema Nervoso Central da Infância. São Paulo: Lemar, ,2003. cap. 16, p. 215.

STUPP, R.; HEGI, M. E.; VAN DEN BENT, M. J. et al. Changing paradigms - An update on the multidisciplinary management of malignant glioma. The Oncologist. v.11, p. 165-180, 2006.

UEKI, K.; ONO, Y.; HENSON, J. W. et al. CDKN2/p16 or RB alterations occur in the majority of glioblastomas and are inversely correlated. Cancer Res, 1996; 56: 150-3.

VERMA, I. M.; SOMIA, N. Gene therapy-promises, problems and prospects. Nature, v.389, n.648, p. 239-24s, 1997.

WATANABE, K.; SATO, K.; BIERNAT, W. et al. Incidence and timing of p53 mutations during astrocytoma progression in patients with multiple biopsies. Clin Cancer Res, v.3, p. 523-30, 1997.

WATANABE, K.; TACHIBANA, O.; SATO, K. et al. Overexpression of the EGF receptor and ph53 mutations are mutually exclusive in the evolution of primary and secondary glioblastomas. Brain Pathol., v., p. 217-24, 1996.

WONG, A. J.; BIGNER, S. H.; BIGNER, D. D. et al. Increased expression of the epidermal growth factor receptor gene in malignant gliomas is invariably associated with gene expression. Proc. Natl. Acad. Sci USA, v.84, p. 6899903, 1987.

Title: Glioblastoma: Conceptual Basis and Future Prospects for TREATMENT

\section{ABSTRACT}

Gliobastomas are neoplasies that present themselves to be the most malignant among the astrocytic tumors. Their prognosis is ominous, with few years of survival. As we are dealing with such an aggressive illness, whose treatment is still so greatly limited, this study has had as objective to carry out a bibliographical revision to clarify the mechanisms of this illness and the advances in its treatment. One concludes that, despite the progress in the treatment of glioblastoma, it is still necessary to achieve more 
advances, by means of current promising researches, thus improving the quality of life of these patients.

KEYWORDS: Glioblastoma; Astrocytic tumors; Tumor suppressor gene; Temozolomide; Gene therapy. 